\title{
Short-acting beta-agonist research: A perspective
}

\author{
Malcolm R Sears MBChB FRCPC \\ McMaster University, Hamilton, Ontario
}

\section{MR Sears. Short-acting beta-agonist research: A perspective. Can Respir J 2001;8(5):349-355.}

Asthma mortality increased sharply in New Zealand in 1977, prompting a national investigation into circumstances of asthma deaths. Subsequent observations of improved asthma control in subjects withdrawn from regular beta ${ }_{2}$ agonist treatment raised the question of whether asthma severity and, therefore, mortality could relate to frequent beta-agonist use. A randomized controlled trial of regular inhaled fenoterol versus as-needed bronchodilator use showed worsened asthma control during regular treatment despite concomitant use of inhaled corticosteroids. Assessment of these findings led to delay in the publishing of the American Asthma Guidelines, which were modified to suggest caution in using beta ${ }_{2}$-agonist treatments. Simultaneously, case control studies in New Zealand suggested that prescription of fenoterol was a substantial risk factor for asthma mortality. The causal association was hotly debated, but increasing evidence pointed to an adverse effect of fenoterol on asthma severity and, hence, mortality. This was supported by dramatic decreases in both morbidity and mortality when fenoterol was effectively withdrawn from use in New Zealand. The link between worsening asthma morbidity and mortality, and the use of potent short-act-

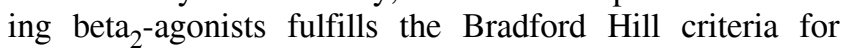
attributing causality. Application of evidence from randomized, controlled trials of short-acting beta-agonist use has led to a major shift in therapy in asthma to the recommendation of as-needed use only of short-acting beta-agonists and decreased patient reliance on regular bronchodilator therapy.

\section{Recherche sur les bêta-agonistes à action brève}

RÉSUMÉ : La mortalité due à l'asthme a augmenté brusquement en Nouvelle-Zélande en 1977, ce qui a mené à une enquête nationale sur les circonstances de ces décès. Par la suite, la meilleure maîtrise de l'asthme observée chez les patients ayant interrompu leur traitement normal aux agonistes $\beta_{2}$ a soulevé la question d'un lien éventuel entre la gravité de l'asthme et, par conséquent, la mortalité, et l'utilisation fréquente de bêta-agonistes. Un essai comparatif contrôlé randomisé du fénotérol inhalé régulier et de l'emploi au besoin d'un bronchodilatateur a montré que la maîtrise de l'asthme était moindre durant le traitement régulier en dépit d'un emploi simultané de corticoïdes inhalés. L'évaluation de ces résultats a incité à retarder la publication des American Asthma Guidelines, qui ont été modifiées de manière à recommander la prudence dans les traitements à l'aide des agonistes $B_{2}$. Au même moment, des études de cas-témoins en Nouvelle-Zélande ont indiqué que la prescription de fénotérol constituait un important facteur de risque de mortalité due à l'asthme. L'association causale a été vivement discutée, mais de plus en plus, les données révèlent un effet défavorable du fénotérol sur la gravité de l'asthme et donc sa mortalité. Cela a été confirmé par des diminutions marquées tant de la morbidité que de la mortalité lorsque l'emploi du fénotérol a été interrompu en Nouvelle-Zélande. Le lien entre l'aggravation de la morbidité et de la mortalité dues à l'asthme et l'utilisation de puissants agonistes $B_{2}$ à action brève répond aux critères de causalité de Bradford Hill. Les résultats d'essais contrôlés randomisés d'emploi de bêta-agonistes à action brève a mené à un changement de cap majeur dans le traitement de l'asthme, soit à la recommandation d'un emploi au besoin seulement des bêta-agonistes à action brève et une utilisation moins régulière des bronchodilatateurs par les patients.

Key Words: Asthma; Beta-agonist; Morbidity; Mortality; Research; Severity

Originally presented as the Wunderly Oration at the 1997 Annual Meeting of the Thoracic Society of Australia and New Zealand (TSANZ), and published in the TSANZ News, September 1997. Reprinted in modified form with permission from TSANZ

Correspondence and reprints: Professor Malcolm R Sears, Firestone Regional Chest and Allergy Unit, St Joseph's Hospital, 50 Charlton Avenue East, Hamilton, Ontario L8N 4A6. Telephone 905-522-1155 ext 3286, fax 905-521-6132,

e-mailsearsm@McMaster.ca 
$\mathrm{M}$ $\mathrm{y}$ interest in asthma mortality and factors underlying the increases in mortality began in 1978, with the sudden death of a 21-year-old youth under my care. He had had asthma since childhood, with several hospital admissions, but achieved good control with normal pulmonary function using theophylline and inhaled cromoglycate. He used inhaled fenoterol for symptom control. At last review, forced expiratory volume in $1 \mathrm{~s}$ was $98 \%$ predicted, and symptoms were minimal. He appeared well on retiring to bed, but at 6:45 his father heard him struggling with severe asthma, and despite emergency measures, the attack was fatal within $10 \mathrm{~min}$.

The occurrence in 1978 of five such sudden deaths in young people in Dunedin, New Zealand, including two patients under my care and apparently well controlled, was a new and alarming problem. Colleagues in other parts of New Zealand reported that they too had seen occasional fatalities, and we concluded that mortality from asthma had increased significantly. It was two to three years later, when national mortality statistics were available, that we realized that the asthma mortality rate among young people in New Zealand had increased to levels higher than ever before seen - the rate in 1977 reached nearly 4.0/100,000 people aged five to 34 years (Figure 1) (1). The upward trend in the whole population was more difficult to interpret from 1979 onwards, because the Ninth Revision of the International Classification of Diseases changed the code for asthma deaths in which bronchitis was also mentioned. The abrupt increase in asthma mortality in 1979 in the total population was an artefact due to this coding change. However, the increase in asthma mortality in young people clearly preceded 1979 and was affected minimally by the International Classification of Diseases.

At the instigation of a number of researchers, the Medical Research Council of New Zealand convened an Asthma Task Force, which initiated the National Asthma

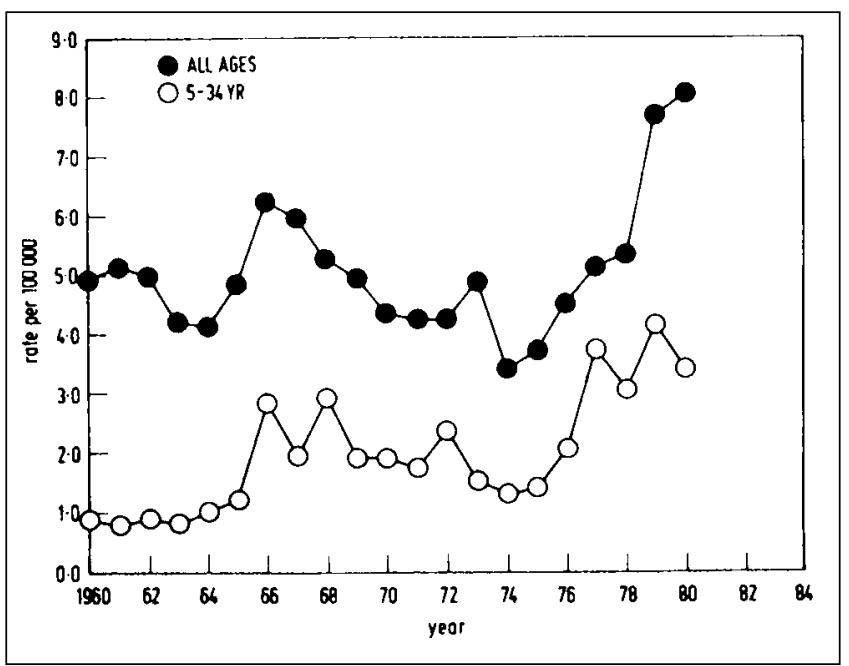

Figure 1) Asthma mortality rates for the New Zealand population and the five to 34 years (YR) age group, 1960 to 1980. Reproduced with permission from reference 1
Mortality Study conducted from 1981 to 1983 (1). In that study, the largest review of asthma mortality anywhere in the world, we investigated all patients noted to have died of asthma anywhere in New Zealand, with detailed investigation into the circumstances of death of individuals aged less than 70 years. We sought to determine whether the subject had indeed had asthma and whether they had died of asthma, its treatment or its complications. If so, we examined the characteristics of the patient, the asthma, the short and long term management of the disease, and the circumstances of death $(2,3)$. Throughout the analyses and subsequent publications of our findings, an unanswered question was 'Why did this person's asthma become so severe that they had a fatal attack?'. The answer was some years away.

In 1984, 20 of my patients participated in a three-month, double-blind, randomized, controlled trial of an allegedly orally active cromoglycate-like drug, sudexanox (unpublished data). Several patients improved substantially throughout the study, and I concluded that they were taking active medication. It transpired, however, that improvement occurred equally in those taking placebo and those taking the active drug. Sudexanox was proven ineffective, and it was not marketed. Reflecting on why some subjects had improved so much during the study despite the overall negative finding, the idea occurred that there might be a connection between the one change made in their medication before commencing the study and the outcome. At that time, many asthmatics were using regular four-times-daily betaagonist treatment, which seemed a logical regimen to 'keep the airways open'. The sudexanox study design required that patients use the beta-agonist only as required for symptom relief. The following question arose: could the pretrial change from regular to as-needed beta-agonist treatment, to meet entry requirements, have resulted in the improvements seen in this study?

In 1986, I spent a sabbatical year at McMaster University in Hamilton, Ontario. Being away from clinical responsibilities with time to read, review and ponder, I explored the hypothesis that regular short-acting beta-agonist treatment may have a deleterious effect in asthma. This hypothesis was based on several factors - the improvement observed in the sudexanox study, the increasing use of regular betaagonists to 'keep the airways open' and to enhance deposition of inhaled anti-inflammatory therapy, the heavy, although not unexpected, use of beta-agonists by those suffering fatal asthma and a few European studies suggesting that beta-agonists may increase airway responsiveness (4-6) . A thorough literature search for evidence in favour of regular beta-agonist efficacy identified only one very short crossover study with one week for each treatment, which showed an apparent benefit of regular four-times-daily bronchodilator treatment over as-needed use (7). During that sabbatical year, I took courses in the Design, Measurement and Evaluation program at McMaster University, and used the question regarding beta-agonists for the research design course: 'Does regular use of beta-agonists have a deleterious 
effect in asthma?'. This moved from a theoretical to a practical exercise as the study, with minor modifications, was submitted to the Medical Research Council of New Zealand in 1987. The study was conducted in Dunedin between 1988 and 1990 as a double-blind, placebo controlled crossover trial, with two treatment periods each of 24 weeks' duration, during which the subject took either fenoterol $400 \mu \mathrm{g}$ or matching placebo four times daily (8-10). Concomitant treatment with inhaled corticosteroid or cromoglycate was maintained constant. Subjects recorded peak flow, symptoms and all drug use. The primary outcome was the period of best asthma control determined by within-subject comparisons of the last 16 weeks of each treatment period.

Both salbutamol and fenoterol were evaluated as a trial drug for the study. The choice of fenoterol was based on three factors. Dry powder inhalers were desirable to exclude the possible effect of propellants on asthma control. Second, active fenoterol and placebo provided by the manufacturer were indistinguishable, whereas we could distinguish dry powder salbutamol from its placebo by taste. Third, Boehringer Ingelheim (Germany) had recently developed a new dry powder inhalator device that was not yet marketed in New Zealand. By using that device, the patients would be more effectively blinded to the fact that the trial medication was a beta-agonist. The choice of fenoterol led to very substantial consequences while the study was in progress.

Because of the question asked, it was imperative that the subjects be blinded to the study design and to the medications being used. This raised ethical issues regarding the withholding of information from the subjects, who were told that they were being treated with currently available drugs rather than new medications. Most subjects believed that they received a different inhaled medication every month when we renewed their fenoterol or placebo capsules, and none were aware that they were taking regular fenoterol for six months. In April 1989, after the work of Crane and colleagues (11) in Wellington, New Zealand, fenoterol was identified in a case-control study as a risk factor for mortality from asthma. We were midway through our study, with incomplete enrollment, in which, for six months, subjects were taking fenoterol in relatively high dose four times daily, unaware that this was the 'trial medication'. We had urgent consultations with our Ethics Committee, who were initially of the view that the trial should be discontinued. Only after hearing persuasive arguments that discontinuing the entire study would be unethical, because there was an imperative need to answer the question of whether fenoterol did or did not affect the severity of asthma, were we permitted to continue the study. The Ethics Committee mandated that no further subjects be recruited, even though we were only at $75 \%$ enrolment, and that subjects taking oral corticosteroid should be withdrawn. Subjects were immediately advised that fenoterol was 'one of the medications' that they were receiving through the trial dry powder inhaler, were told the findings of the study published by Crane et al, and were reassured that we and our Ethics Committee were sat- isfied that it was both safe and important to continue the study.

The final patient completed the study in April 1990, by which time the controversy over fenoterol as a factor in asthma mortality was raging back and forth in the medical literature and the media. While still blinded, we determined, for each subject, whether there was a significant difference in the control of asthma between the two treatment periods and then broke the code. Despite it being our initial hypothesis, we were still surprised to find that the majority of patients showed better asthma control during the placebo period and deteriorated during regular fenoterol treatment, with lower lung function and greater airway responsiveness. As we checked and rechecked the data, we became increasingly aware of the importance of this finding in not only changing the bronchodilator approach to management of asthma, but also explaining the increased morbidity and mortality associated in time with the introduction of fenoterol in New Zealand (Figure 1) (12).

We now had a further dilemma. Our study indicated that a commonly used preparation may have been doing more harm than good because of the way it was being used. We had a scientific study to be written up and published. We had a responsibility to our colleagues and to our patients $-\mathrm{a}$ responsibility to advise against using medication in a manner that may be harmful and yet not to alarm patients by raising fears about a treatment that many had come to depend on for symptomatic relief of a chronic illness. While we urgently prepared a paper for publication, we also sought an independent review of the data.

We faxed a draft paper to Professor Sonia Buist three weeks after the study code was broken. Unknown to us, Dr Buist was a consultant on the National Asthma Education Program of the United States National Health Lung and Blood Institute (NHLBI), which was preparing the American Guidelines for Asthma Management. Those guidelines recommended the use of regular beta-agonist treatment for management of chronic asthma. Dr Buist now had a new dilemma. The guidelines were in final draft, but she now had access to a study that indicated that regular beta-agonist treatment, at least with fenoterol, was deleterious. With our consent, she made the findings of our study known to the NHLBI panel. The publication of the American Guidelines was delayed by several months to allow the results of our study to be critically reviewed after publication in The Lancet. The American guidelines were amended to suggest caution with regular beta-agonist treatment in asthma management (13).

In the meantime, the Wellington group continued their studies on fenoterol and asthma mortality, and published two further case-control studies, responding to various criticisms of study design $(14,15)$. Both indicated an increased risk of asthma death associated with fenoterol compared with salbutamol and suggested that the result was not due to confounding by severity. As a result of the increasing evidence against fenoterol, the New Zealand Department of 


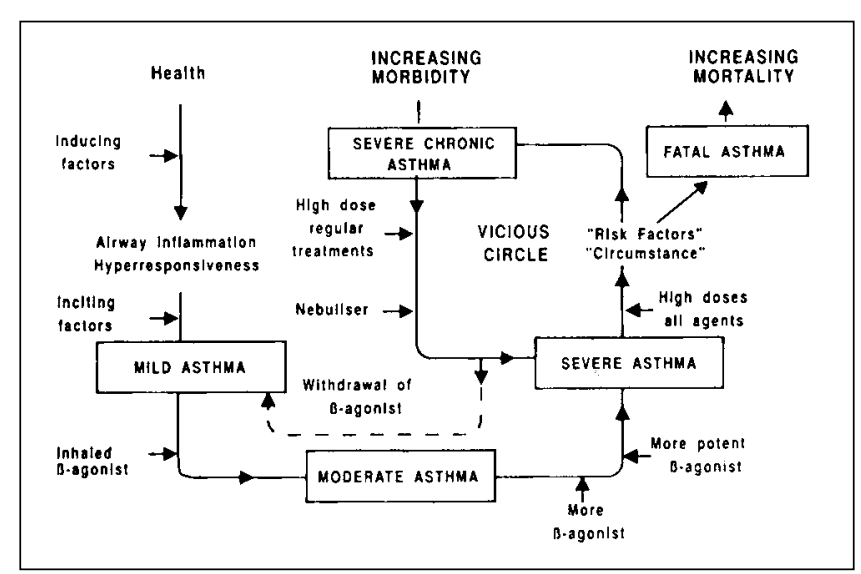

Figure 2) A suggested sequence of events to explain increased morbidity and mortality from asthma as a result of a gradual increase in asthma severity due to the effects of chronic beta-agonist therapy. Reproduced with permission from reference 26

Health removed fenoterol from the list of readily accessible medications in 1990.

At the instigation of Boehringer Ingelheim and in response to the findings of the first New Zealand case control study, Spitzer and colleagues (16) embarked on a large case-control study in Saskatchewan. Saskatchewan has a computerized pharmaceutical database, so that prescriptions for asthma could be readily tracked to individuals. This province-wide, eight-year, retrospective review of deaths and near-deaths from asthma found a higher risk associated with the use of fenoterol than salbutamol but did not exonerate salbutamol, as had the Wellington studies. Heavy use and a pattern of recent increasing use were markers of high risk (17). Each additional canister of beta-agonist used per month increased the risk of death 2.6-fold, and a doubling of beta-agonist use over six months was a marker for a lifethreatening episode. Again, this epidemiological study could not ascribe causality with certainty. Many regarded the results to be due to confounding by severity, in that those with more severe asthma and, therefore, at greater risk of death were prescribed higher doses of more potent betaagonists.

Several hypotheses were proposed to explain the apparent link between excessive beta-agonist use and asthma mortality. High doses of beta-agonist can induce cardiac and metabolic changes, more so with fenoterol and isoprenaline than with salbutamol, raising the possibility that the epidemics of asthma mortality were linked to fatal cardiac arrhythmias developing under conditions of hypoxia during acute asthmatic episodes when high doses of beta-agonist may be used $(18,19)$. Our study and subsequent independent studies $(8-10,20-22)$ suggested that the long term use of high doses of beta-agonists increased the severity of asthma and hence could increase the risk of a fatal episode. Colleagues in Auckland, New Zealand vigorously denied a causal association between fenoterol use and mortality, and suggested that the link was purely due to confounding by severity (23). Still others, especially those outside New Zealand, suggested that the link between beta-agonists and mortality was related to access to care and inadequate use of inhaled corticosteroids, and that reliance on beta-agonists was a manifestation of poor quality of asthma care in New Zealand (24). However, Keating and colleagues (25) had, some years earlier, provided data showing that, in the early years of the epidemic, New Zealand used more inhaled corticosteroid per capita than Australia and the United Kingdom, effectively negating that hypothesis.

It seemed to us that there was a plausible hypothesis that explained the observations of all groups of investigators working in the asthma mortality and/or beta-agonist field $(12,26)$. An increasing number of studies indicated that the regular use of inhaled beta-agonists increased airway responsiveness to nonspecific challenge agents, and our own study showed that regular fenoterol use increased the severity of asthma. Hence, the link between high use of beta-agonists and death from asthma was likely not solely due to confounding by severity, but reflected an adverse effect of an asthma treatment that increased the severity of asthma. We developed the model of a vicious circle of adverse effects of beta-agonists (Figure 2), in which the use of beta-agonists gradually increased the severity of the disease, increasing morbidity (reflected in hospital admissions) and increasing the number of people with more severe asthma at risk of a fatal episode if they were in circumstances without good or prompt asthma care (26).

The 'vicious circle' hypothesis proved to be quite controversial. As Sonia Buist predicted when she first learned of our results, there was substantial resistance to publication of opinions that threatened physician comfort with what was widely regarded as the appropriate way to manage asthma. Reviewers were very critical of our hypothesis and recommendations to reduce beta-agonist use. One reviewer of our paper wrote: "The idea that the gradual increase in baseline mortality observed in many countries over the last decade or more may be explained by the increasing use of betaagonists is odd coming from a New Zealander." Another reviewer wrote: "If their hypothesis that the withdrawal of beta-agonists can be safely accomplished in all patients is incorrect, and their advice is followed, then this may lead to disastrous results."

On the other hand, our experience in stabilizing asthmatics by reducing excessive beta-agonist use reinforced the validity of the hypothesis. Many patients improved substantially using strategies aimed at reducing their use of betaagonists, with less variability in daily peak flow and less need for symptom relief, often with lower, rather than higher, doses of inhaled corticosteroid (Figure 3).

In the United States, the Asthma Clinical Research Network undertook a multicentre study funded by NHLBI to determine whether regular salbutamol treatment was appropriate as monotherapy in mild asthma (27). This study was a parallel-group comparison in subjects with relatively mild asthma, with few exacerbations, but the findings were 

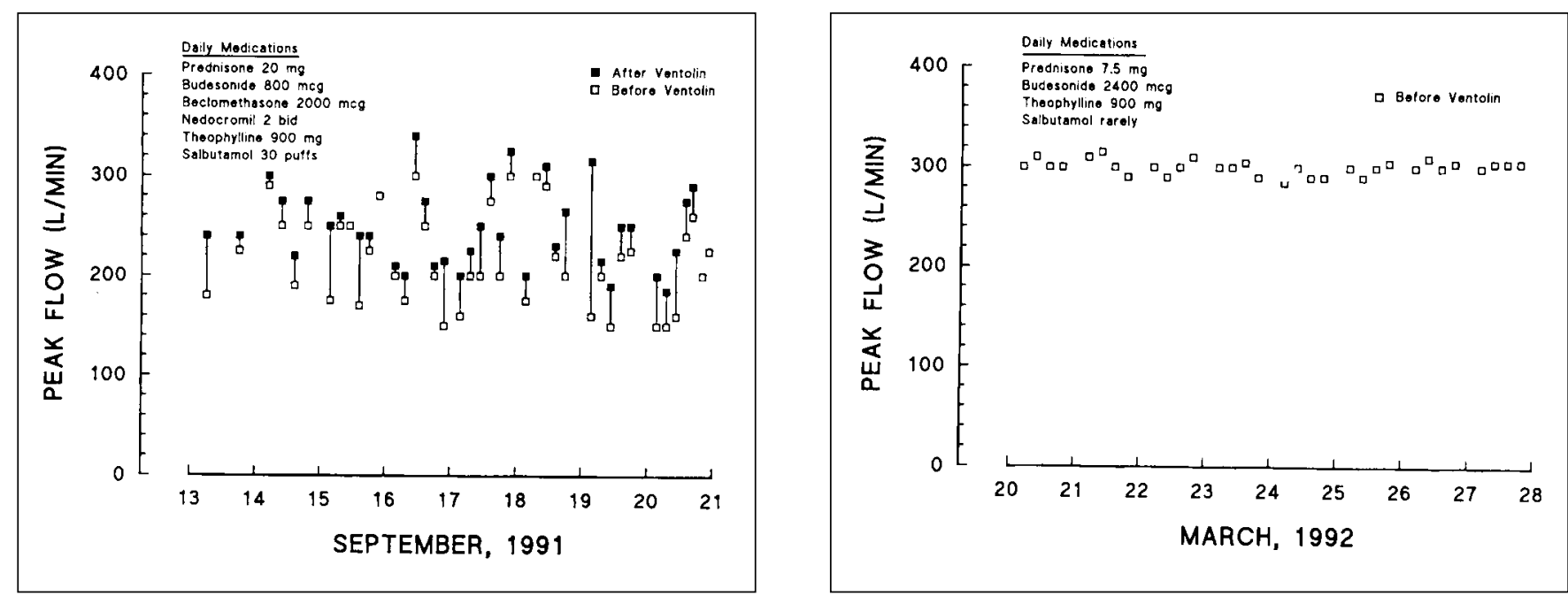

Figure 3) Peak flow variability and medication requirements before (September, 1991 [Left]) and after (March, 1992 [Right]) weaning from frequent use of salbutamol in a patient with 'brittle' asthma

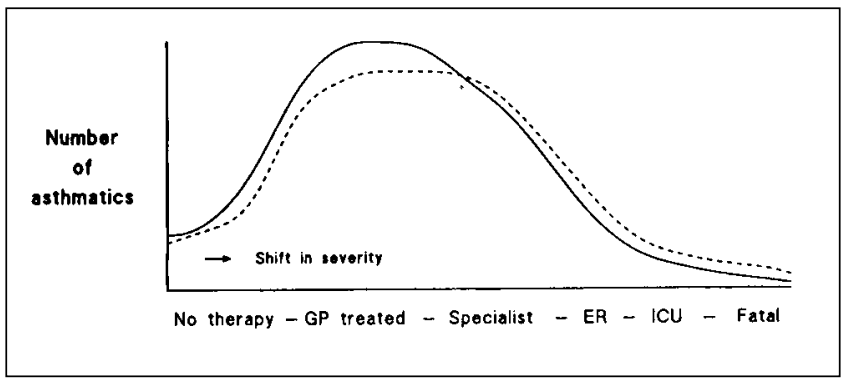

Figure 4) The effect of a small shift in severity of asthma resulting in more emergency room (ER) visits, hospital admissions and deaths. The solid line represents a suggested baseline spectrum of severity, and the broken line represents the effect of a small increase in severity across all asthmatic patients, which would be recognized primarily by increased numbers of asthmatic patients with more severe disease. GP General practitioner; ICU Intensive care unit. Reproduced with permission from reference 12

similar to those of the New Zealand study. In all parameters studied, there was a slight but insignificant difference, suggesting deterioration during regular treatment, with only one statistically significant difference, a shift in airway responsiveness of the same magnitude as found in the Dunedin study. Although the changes observed in these subjects with mild asthma, who were not receiving any other antiasthma medications, were small, the findings are consistent with the concept that beta-agonists can alter severity.

The American study added yet another data point to the many studies now indicating that beta-agonist use can increase airway hyper-responsiveness in asthmatics (28). Overall, the American study reinforced the view that the regular or frequent use of beta-agonists can cause a small shift in severity of disease - almost imperceptible in the majority of patients, who have mild or moderate disease, but a very important shift in patients with more severe disease, who are at greatest risk of adverse events. In these patients,

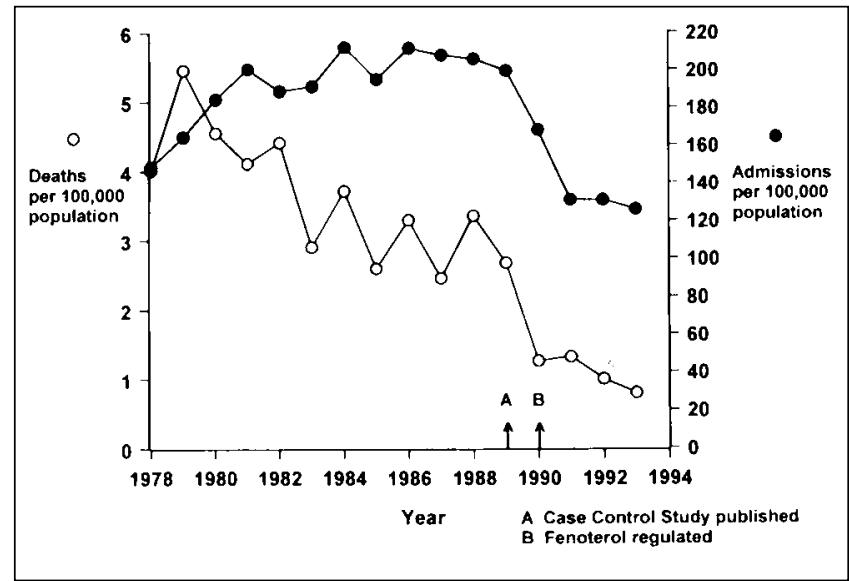

Figure 5) Abrupt decrease in asthma-related hospital admissions and mortality in New Zealanders aged 15 to 44 years after withdrawal of fenoterol in 1990. Reproduced with permission from reference 28

an increase in severity can have major consequences. Substantial increases in morbidity and even mortality would be expected to accompany an increase in severity when the patient is already at the severe end of the asthma spectrum (Figure 4).

After the effective removal of fenoterol in New Zealand, there was a marked reduction in both asthma mortality and hospital admissions, very strongly suggesting a link between beta-agonists and both morbidity and mortality (Figure 5) (29). Although several hypotheses had been put forward to explain this link, it was evident that the cardiac hypothesis could not explain the abrupt fall in hospital admissions when fenoterol was withdrawn. There were many initiatives in the 1980s that helped to decrease the peak of the extremely high mortality rate, including increased availability of peak flow meters, national education campaigns, provision of educational material, training of nurse educators, publication of self-management plans, 
and improved clinic and community management strategies. These management strategies and educational activities contributed to the partial reduction in mortality rates from 1983 to 1988, during which time hospital admissions continued to increase. However, the abrupt fall in both mortality and hospital admissions that began in 1989 and was very evident by 1990 cannot be explained by these measures. Rather, this abrupt fall clearly indicates a major change in the severity of the disease. This is fully consistent with the hypothesis that fenoterol increased the severity of asthma, and that when concern was raised about its safety in 1989 and more so in 1990 on its withdrawal, severity decreased, reducing both morbidity and mortality.

Over 30 years ago, Bradford-Hill (30) proposed nine criteria - strength, consistency, specificity, temporality, biological gradient, plausibility, coherence, experiment and analogy - for attributing causality to associations observed in epidemiology. The epidemiological studies associating beta-agonist use with mortality and experimental studies of the chronic effects of beta-agonists increasing asthma severity provide most of these nine criteria required to link betaagonists with mortality (12). The studies are internally and externally consistent, relate specifically to certain agents in respect to epidemics, show appropriate time trends in two epidemics, show dose-response gradients in the Saskatchewan study and are supported by experiments in randomized, controlled studies of asthma severity. There does appear to be plausibility, strength and coherence in the data now available.

Pharmaceutical companies, with some tardiness, accepted that frequent, high-dose beta-agonist treatment is not appropriate in asthma management. Boehringer Ingelheim replaced their $200 \mu \mathrm{g}$ fenoterol inhaler with a $100 \mu \mathrm{g}$ inhaler. Glaxo Wellcome (United Kingdom) promoted salbutamol as a 'rescue' inhaler, not for regular use. Even some of the most vocal critics of the link between short-acting beta-agonists and asthma mortality have recently accepted these findings. Clinicians and research scientists now agree that there is a problem with the frequent use of short-acting beta-agonists, which is doseand potency-dependent, and which affects morbidity and mortality. The mechanism of the adverse effects is established to be related to the severity of asthma and not to cardiac events induced by beta-agonists.

\section{WHAT LESSONS CAN BE LEARNED FROM THE BETA-AGONIST DEBATE?}

First, short-acting beta-agonists are necessary drugs, very useful in the management of acute asthma and as rescue treatment for rapid bronchodilation, and useful for treating intermittent symptoms that break through other treatments. However, the studies reviewed strongly suggest that too much of a good drug may be deleterious. After 30 years of debate, virtual consensus as to the role of these agents has finally emerged.

Second, these studies and debates have illustrated the need to link several different types of study to answer a question - associations may be apparent from epidemiology, but randomized, controlled trials are required to establish causality and determine mechanisms. Research studies were triggered by observations and by results emerging from previous studies, even from apparently inconsequential negative studies. Complex networks of studies over many years may finally lead to altered understanding and management of chronic diseases.

Third, long term studies may provide different outcomes than short term studies. In asthma, it is no longer sufficient to look at $6 \mathrm{~h}$ or six-day or six-week studies, but long term outcome studies over months and years are required to determine optimum management.

Fourth, research can be very cost effective. The New Zealand studies described cost less than $\$ 1$ million, but the reduction in mortality resulting from the identification of the major cause of the second epidemic, allowing for a very conservative savings of $\$ 100,000 /$ life saved, resulted in total savings of over $\$ 10$ million/annum. This does not take into account the savings in costs of hospital admissions and other treatments of acute severe asthma.

Finally, clinical practice must be 'evidence-based'. What may seem to be a good idea, such as the regular use of an inhaled bronchodilator to 'keep airways open', may not prove to be appropriate when put to clinical trial. We need to keep reviewing practices and policies, and to challenge traditions and prior beliefs, in our search for the best evidence on which to base the management of patients. Some of the implications of beta-agonist research were threatening both to the medical profession and to pharmaceutical companies, and it was difficult to avoid the tensions and concerns that arose in those circumstances. However, the results obtained from the many studies conducted on betaagonists, and asthma morbidity and mortality over the past decade have brought us to a closer agreement on a new understanding of the role of short-acting beta-agonists than might have seemed possible as the saga unfolded.

\section{REFERENCES}

1. Sears MR, Rea HH, Beaglehole R, et al. Asthma mortality in New Zealand: a two year national study. N Z Med J 1985;98:271-5.

2. Rea HH, Sears MR, Beaglehole R, et al. Lessons from the national asthma mortality study: circumstances surrounding death. N Z Med J 1987;100:10-3.

3. Sears MR, Rea HH, Fenwick J, et al. 75 deaths in asthmatics prescribed home nebulisers. Br Med J 1987;294:477-80.

4. Kraan J, Koeter GH, van der Mark THW, Sluiter HJ, de Vries K. Changes in bronchial hyperreactivity induced by 4 weeks of treatment with antiasthmatic drugs in patients with allergic asthma: a comparison between budesonide and terbutaline.

J Allergy Clin Immunol 1985;76:628-36.

5. Kerrebijn KF, van Essen-Zandvliet EEM, Neijens HJ. Effect of long-term treatment with inhaled corticosteroids and beta-agonists on the bronchial responsiveness in children with asthma. J Allergy Clin Immunol 1987;79:653-9.

6. Vathenen AS, Higgins BG, Knox AJ, Britton JR, Tattersfield AE. Rebound increase in bronchial responsiveness after treatment with inhaled terbutaline. Lancet 1988;i:554-8.

7. Shepherd GL, Hetzel MR, Clark TJH. Regular versus symptomatic aerosol bronchodilator treatment of asthma. Br J Dis Chest 1981;75:215-7. 
8. Sears MR, Taylor DR, Print CG, et al. Regular inhaled beta-agonist treatment in bronchial asthma. Lancet 1990;336:1391-6.

9. Taylor DR, Sears MR, Herbison GP, et al. Regular inhaled $\beta$-agonist in asthma: effect on exacerbations and lung function. Thorax 1993;48:134-8.

10. Ellman MS, Viscoli CM, Sears MR, Taylor DR, Beckett WS, Horwitz RI. A new index of prognostic severity for chronic asthma Chest 1997;112:582-90.

11. Crane J, Pearce N, Flatt A, et al. Prescribed fenoterol and death from asthma in New Zealand, 1981-83: Case-control study. Lancet 1989;i:918-22.

12. Sears MR, Taylor DR. The $\beta 2$-agonist controversy. Observations, explanations and relationship to asthma epidemiology. Drug Saf 1994;11:259-83.

13. National Asthma Education Program, National Institutes of Health. Guidelines for the Diagnosis and Management of Asthma. Publication No 91-3042. Bethesda: United States Department of Health and Human Services, 1991.

14. Pearce N, Grainger J, Atkinson M, et al. Case-control study of prescribed fenoterol and death from asthma in New Zealand, 1977-81. Thorax 1990;45:170-5.

15. Grainger J, Woodman K, Pearce N, et al. Prescribed fenoterol and death from asthma in New Zealand, 1981-7: a further case-control study. Thorax 1991;46:105-11.

16. Spitzer WO, Suissa S, Ernst P, et al. The use of $\beta$-agonists and the risk of death and near death from asthma. N Engl J Med 1992;326:501-6.

17. Suissa S, Ernst P, Boivin J-F, et al. A cohort analysis of excess mortality in asthma and the use of inhaled beta agonists. Am J Respir Crit Care Med 1994;149:604-10.

18. Crane J, Burgess C, Beasley R. Cardiovascular and hypokalaemic effects of inhaled salbutamol, fenoterol, and isoprenaline. Thorax 1989;44:136-40.

19. Bremner P, Burgess CD, Crane J, et al. Cardiovascular effects of fenoterol under conditions of hypoxaemia. Thorax 1992;47:814-7.

20. Cockcroft DW, McPaarland CP, Britto SA, Swystun VA, Rutherford BC. Regular inhaled salbutatmol and airway responsiveness to allergen. Lancet 1993;342:833-7.

21. Cockcroft DW, O'Byrne PM, Swystun VA, Bhagat R. Regular use of inhaled albuterol and the allergen-induced late asthmatic response. J Allergy Clin Immunol 1995;96:44-9.

22. Inman MD, O'Byrne PM. The effect of regular inhaled albuterol on exercise-induced bronchoconstriction. Am J Respir Crit Care Med 1996;153:65-9.

23. Garrett JE, Lanes SF, Kolbe J, Rea HH. Risk of severe life threatening asthma and $\beta$-agonist type: an example of confounding by severity. Thorax 1996;51:1093-99.

24. Ziment I. Beta 2 agonists and their antagonists. Chest 1994;106:329-31.

25. Keating G, Mitchell EA, Jackson R, Beaglehole R, Rea H. Trends in sales of drugs for asthma in New Zealand, Australia and the United Kingdom 1975-81. Br Med J 1984;289:348-51.

26. Taylor DR, Sears MR. Regular beta-adrenergic agonists. Evidence, not reassurance, is what is needed. Chest 1994;106:552-9.

27. Drazen JM, Israel E, Boushey HA, et al. Comparison of regularly scheduled with as-needed use of albuterol in mild asthma. N Engl J Med 1996;335:841-7.

28. Taylor DR, Sears MR. Bronchodilators and bronchial hyperresponsiveness. Thorax 1994;49:190-1.

29. Sears MR. Epidemiological trends in asthma. Can Respir J 1996;3:261-8.

30. Bradford-Hill A. The environment and disease: association or causation? Proc R Soc Med 1965;58:295-300. 


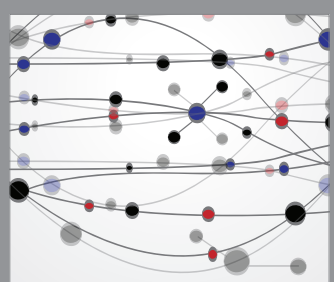

The Scientific World Journal
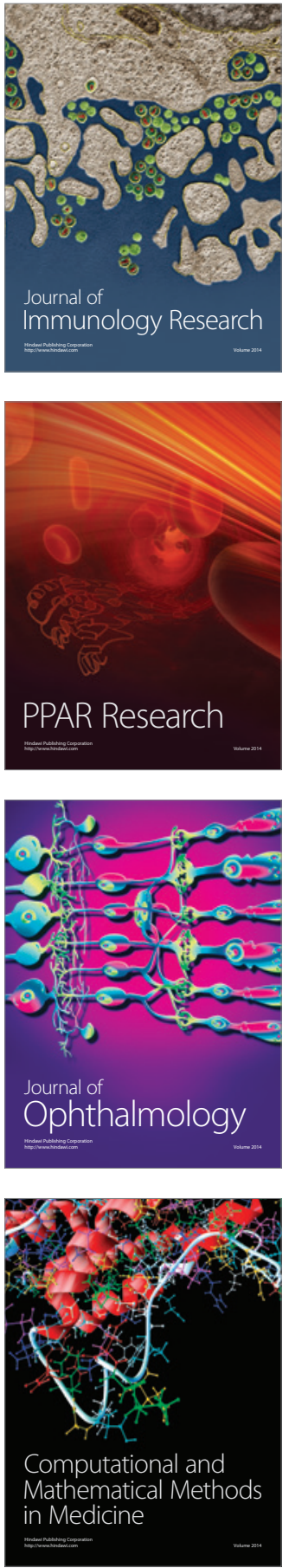

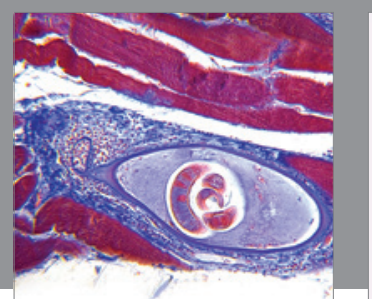

Gastroenterology Research and Practice

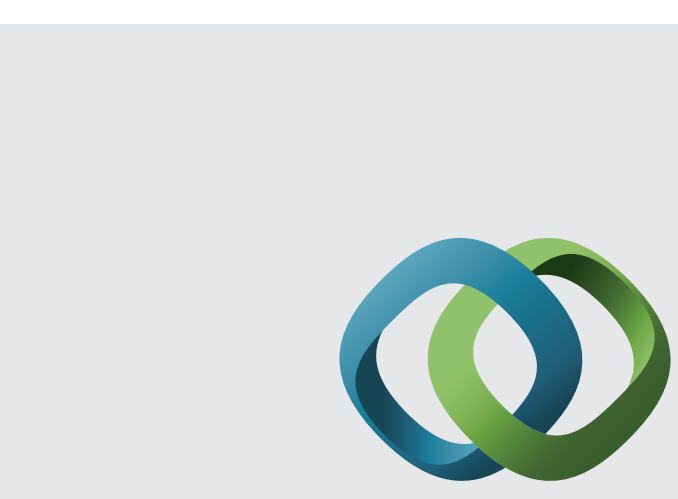

\section{Hindawi}

Submit your manuscripts at

http://www.hindawi.com
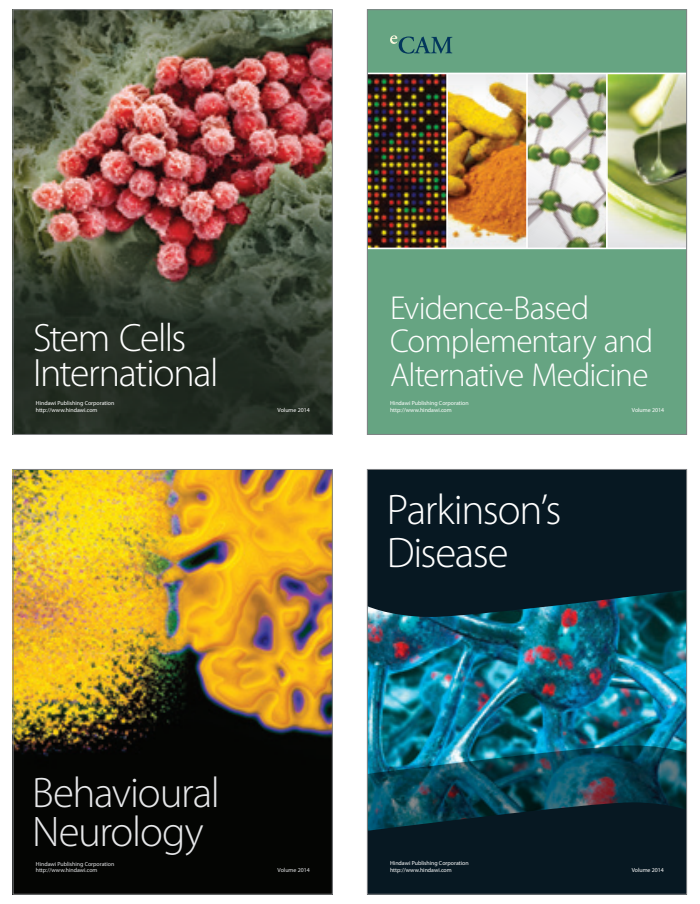
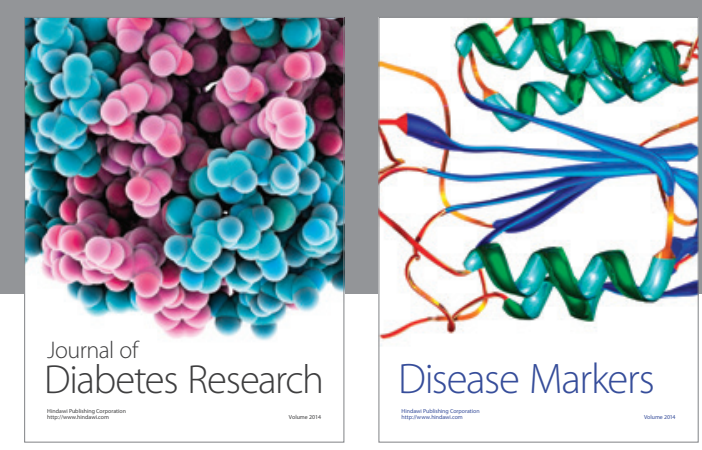

Disease Markers
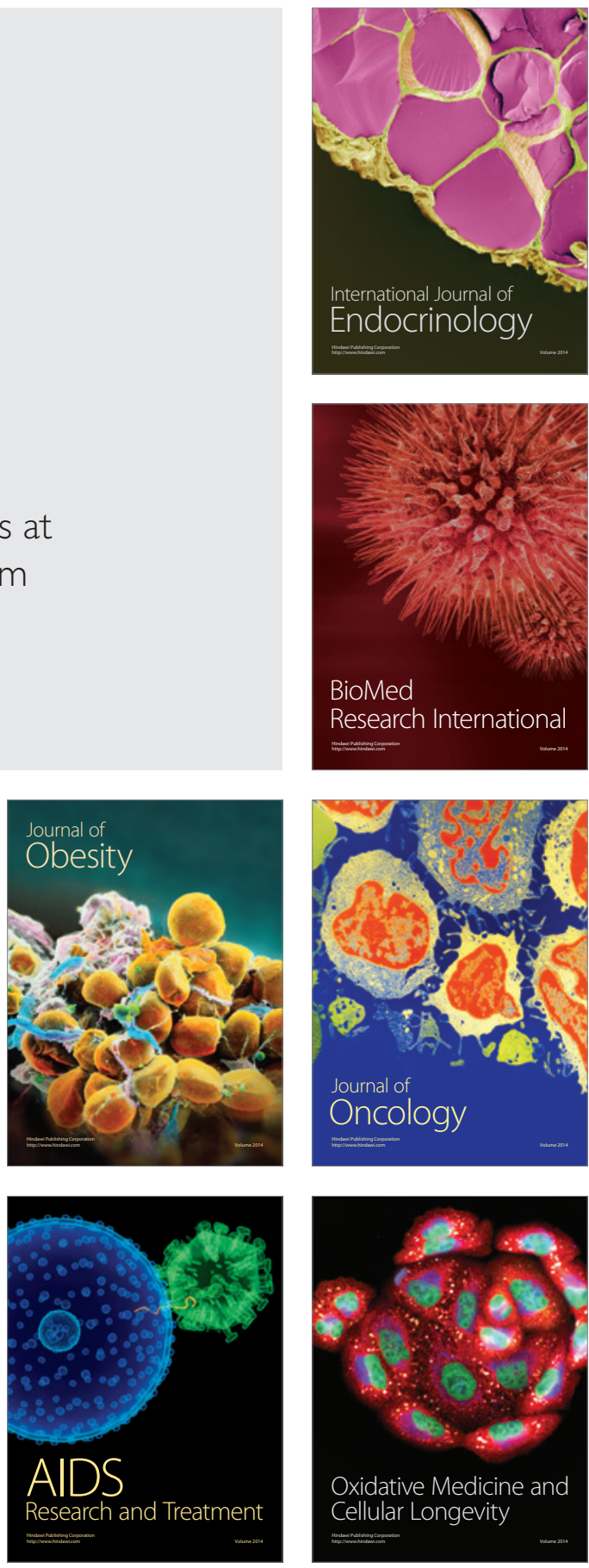